\title{
Research on Enterprise Accounting Cost Accounting and Control under the Background of Economic Globalization
}

\author{
Zijun Wang, Guangming Wang* \\ Nanjing university of science and technology, Nanjing 210000, China \\ *Corresponding author email: jshawzj@126.com
}

\begin{abstract}
In the context of popular innovation and entrepreneurship, small and medium-sized enterprises have become the core carrier of national economic development. The current integration of the global economy has prompted small and medium-sized enterprises to face both domestic and foreign competitive market pressures. Therefore, small and medium-sized enterprises need to strengthen production and operation on the one hand, and carry out good management and control of accounting costs on the other. It can be said that the current accounting costs are Control is already related to the sustainable development and steady progress of SMEs. This article defines the environmental cost of enterprises, analyzes the dilemma of the enterprise's application of environmental cost accounting and control system, and finds an effective way for the application of environmental cost accounting and control system to enterprises.
\end{abstract}

Keywords: Economic Globalization; Corporate Accounting; Cost Accounting and Control; ActivityBased Costing.

\section{Introduction}

As the name suggests, accounting financial accounting is traditional accounting that focuses on financial data accounting. It is usually called external accounting. The focus of its work is to disclose accounting information inside and outside the enterprise, and to show various financial conditions such as enterprise assets, liabilities, and income through the preparation of accounting statements. Management accounting is different. Because it focuses more on management services, it focuses on the internal management activities of the enterprise, so it is also called internal report accounting or internal accounting [1]. Although part of the work of management accounting involves traditional financial accounting data and information, it pays more attention to serving the corporate macro strategy and decision-making planning. Since the Ministry of Finance's "Guiding Opinions on Comprehensively Promoting the Construction of the Management Accounting System" was issued in 2014, the transition from accounting-based financial accounting to management accounting has become the basic direction for accelerating the reform of accounting work.

\section{The necessity of doing a good job of cost accounting and control}

On the basis of the continuous improvement of the market economy system, the competition among enterprises has become more and more fierce. In this fierce competition mode, if an enterprise wants to achieve comprehensive development, it must improve its own comprehensive strength, which has a direct impact on the comprehensive strength of the enterprise The part is the business activities of the enterprise and the management ability of the enterprise, especially the financial management work [2]. Effective financial management can further enhance the economic activity income of the enterprise and realize the reasonable allocation of resources and funds. The main purpose of financial management is to improve the economic benefits of the enterprise through the rational use of funds and resources, and the accounting and costing and control of which play a vital role. This shows that if you want to improve the economic strength of an enterprise, you must start with improving the level of accounting cost accounting and control of the enterprise.

Accounting costs refer to the funds used by an enterprise in carrying out economic and business activities. The utilization rate of these funds has a direct impact on the economic benefits and profits of the enterprise. For this reason, in order to ensure the effective growth of an enterprise's economic 
strength and enhance its competitive advantage in the market, it is necessary to strengthen investment in accounting cost accounting and control, ensure effective control of operating costs, maximize capital utilization, and ensure Further development of the corporate economy [3]. The effective development of enterprise accounting cost accounting and control work can not only prompt the economic benefits of the enterprise, but also ensure the rational use of funds and ensure the long-term stable development of the enterprise.

\section{Problems in product cost accounting of SMEs}

There are various problems in the cost accounting process of small and medium-sized enterprises, which can be divided into the following aspects for analysis: First, the lack of a sound financial system among small and medium-sized enterprises will cause considerable disadvantages to the flow of funds. In some enterprises, the role of the financial department is even ignored, and no special accounting personnel are used to deal with it, which affects the comprehensiveness of financial vouchers. In this case, it has caused tax evasion and tax evasion to a large extent. The phenomenon. Secondly, there is no comprehensive design for the product in the design stage. As an enterprise, it is necessary to use advanced technology to reduce production costs, thereby creating greater benefits. However, in many enterprises, the product design has not been scientifically and rationally designed, and they are blindly pursuing upgrades [4]. Therefore, in this case, there is no room for improvement in the technical level of the enterprise. In addition, among enterprises, the cost accounting method is relatively backward. It is affected by the characteristics of the enterprise itself, and has not made long-term considerations. It has not maintained a high degree of emphasis on the financial management of the enterprise. Therefore, the cost accounting part has only stayed at the elementary level. Finally, in enterprises, it is necessary to use professional accounting personnel to perform calculations. Thinking of the quality of talents is the first problem to be solved. In these small-scale small and medium-sized enterprises, there are no professional accounting personnel in the accounting cost calculation. At times, loopholes and problems are prone to appear, which affects the accuracy of cost accounting.

\section{Accounting and control methods of SMEs' accounting costs in the context of big data}

\subsection{Adopt reasonable accounting costing methods}

Whether the accounting cost calculation method is reasonable will have a direct impact on the quality and efficiency of accounting calculations, and it is necessary to choose a specific accounting method based on the actual state of the enterprise. First of all, SME accountants need to grasp the advantages and disadvantages of different accounting methods, determine the applicable scope of accounting cost accounting, and consider the actual problems in accounting cost accounting [5]. Secondly, the cost accountant needs to understand the actual situation of the enterprise, so as to choose the accurate accounting technology according to the actual situation, so as to effectively reduce the accounting workload, improve the accounting accuracy, and ensure the applicability of the accounting technology. Third, when performing accounting cost accounting, it is necessary to ensure the stability of the accounting work, and not to easily change the accounting technology to ensure consistency with the accounting work. Finally, under the information environment, the revision of cost accounting is completed through big data accounting cost accounting technology.

\subsection{Ways to strengthen accounting cost control}

Under normal circumstances, accounting costs are all costs involved in the daily operation of small and medium-sized enterprises. The generation of accounting costs has high dynamic characteristics. Under the background of big data, small and medium-sized enterprises need to control accounting cost accounting in various environments, as detailed below analyze: 


\subsubsection{In terms of purchasing raw materials}

Small and medium-sized enterprises can achieve effective accounting control of accounting costs through cloud computing in a big data environment. They analyze from the perspective of purchasing raw materials and mainly rely on cloud computing technology to ensure the accuracy and completeness of relevant raw material data information, which provides for the establishment of a good purchasing environment. in accordance with. On the one hand, small and medium-sized enterprises can use cloud computing technology to understand the prices and quality of various raw materials they need. On the other hand, they can also release procurement information, expand the procurement channels of raw materials, and reduce the distance between supply and demand of raw materials, thereby improving procurement efficiency and making purchases [6]. The cost is as low as possible. When selecting suppliers, SMEs can promote their own advantages in purchasing raw materials through open competition. High procurement prices will put pressure on the operating costs of SMEs. The use of cloud computing technology can build a corresponding information database for SMEs' raw materials. Analyze the real-time changes in the market prices of raw materials and come up with the best procurement plan. After selecting a supplier, the procurement quantity needs to be reported for approval.

\subsubsection{In terms of logistics}

In the context of big data, small and medium-sized enterprises can effectively control accounting costs through cloud computing. They can also start from the logistics aspect. Both the past and current logistics of small and medium-sized enterprises will account for a large proportion [7]. According to relevant data, you can see The costs involved in the transportation process generally account for $60 \%$ of accounting costs, thus verifying the criticality of transportation to the logistics of small and medium-sized enterprises. With the help of cloud computing platform, logistics operation and procurement can be separated to complete the management of the logistics supply chain. Under normal circumstances, basically all links in the operation of an enterprise are related to logistics costs, so logistics cost control is very important, and cloud computing technology can achieve effective control of all links in the supply chain and reduce logistics costs. In addition, the control of transportation costs can improve the transportation capacity of small and medium-sized enterprises per unit time, plan transportation routes in advance, select the optimal path, and minimize logistics costs.

\subsubsection{In terms of inventory management}

In the context of big data, small and medium-sized enterprises can use cloud computing technology to effectively calculate and control accounting costs. They can also be analyzed from the management of inventory. Small and medium-sized enterprises also involve inventory costs in terms of accounting cost control, and inventory costs are also important for the entire accounting cost. Control elements, usually purchase raw materials according to order requirements. In the context of big data, inventory is realized on the basis of MRP. The actual purchase amount is determined according to the current inventory and bill of materials, and the current goal of minimizing inventory costs provides guarantee for the operation and production of small and medium-sized enterprises. It can also provide early warning for the inventory shelf life and safety stock. Small and medium-sized enterprises usually collect raw material inventory data in order to prevent work stoppages during their operations. Historical manual accounting is prone to errors in raw materials. In addition, it also requires a lot of manpower and material resources, which has a negative impact on corporate decision-making [8]. In the context of big data, small and medium-sized enterprises can paste storage materials, which is actually the only code of materials, which contains detailed storage information. Small and mediumsized enterprises can complete the information management of inventory materials based on this. Warehouse management related workers can also follow The electronic tag realizes the rapid positioning of the goods, whether it is the application of materials or the operation, it can achieve dynamic management, prevent the loss or theft of materials, and minimize the inventory cost. 


\subsubsection{Manufacturing production}

In the context of big data, accounting and control of accounting costs through cloud computing can also be analyzed from the perspective of manufacturing and production. After analyzing the cost composition of the production stage, small and medium-sized enterprises can extract some controllable and frequently occurring key cost indicators to help the cloud computing platform establishes a database of cost indicators to control accounting costs. In addition, the cloud computing platform can also analyze the standard costs corresponding to various processes. Since the standard cost and the corresponding actual cost are very different, it is necessary to analyze the actual reasons for the different situations, and at the same time, the standard the cost-related data is adjusted in time to better fit the actual situation. If abnormal costs are incurred in the daily production process, they need to be resolved through cooperation between different departments to control the abnormal costs, and use the above methods to control the production costs of small and medium-sized enterprises under the background of big data to the lowest level.

\subsubsection{Product sales}

In the context of big data, small and medium-sized enterprises use cloud computing technology to calculate and control accounting costs. They also need to analyze product sales. Through cloud computing technology, small and medium-sized enterprises can complete scientific analysis and tracking of customer needs in the context of big data. Able to design automated new marketing programs through the network, gradually shorten the communication interval between end customers and small and medium-sized enterprises, analyze customer preferences and corresponding needs on this basis, push information for target customers, reduce publicity costs, and reduce advertising costs through cloud computing technology The cost of sales is well calculated.

\section{Case analysis}

Large-scale energy and chemical companies usually have multiple factories and multiple production lines, and generally share power and energy production devices such as water, electricity, and gas, as well as environmental protection devices, etc. with similar geographical locations; in addition, differences in processing raw materials, intermediate products and final products Variety and quantity differences, as well as the distribution of period expenses, make traditional cost accounting methods unable to effectively meet the refined needs of enterprise cost management and timely grasp of the profit contribution of each product.

\subsection{Cost driver selection and consumption calculation based on activity-based costing}

The direct material cost, labor cost, manufacturing cost and other cost accounting still adopt the traditional method, but the indirect cost allocation method adopts the activity-based costing method.

\subsubsection{Consumption of raw materials and power and energy}

Usually, the consumption of production equipment (final products) is directly used as the cost driver. For the consumption of auxiliary production workshops and management departments in the shared mode, the output of the product is used as the cost driver. Production assistance and management department consumption $=($ product output $/$ product total $) \times$ total consumption .

\subsubsection{By-products}

A certain production device (line) of an energy chemical enterprise can usually produce multiple by-products. There are multiple production devices coexisting and producing different final products. Therefore, it is more suitable for the by-products to adopt the method of reclining the cost of sales revenue. 


\subsubsection{Depreciation and amortization}

For a single production device itself, depreciation and amortization shall be carried out in accordance with the accounting regulations of the enterprise. For the production auxiliary workshops and management departments that adopt the shared mode, depreciation and amortization choose the final product output as the cost driver. The more final products produced by a single device, the consumption of the shared mode production auxiliary workshop and the fixed assets ratio of the management department the larger the value, the larger the depreciation and amortization. Product depreciation and amortization $=($ product output $/$ product total $) \times$ total depreciation expenses.

\subsubsection{Selling expenses}

Sales expenses incurred by sales personnel classified by product are directly included in the cost of product sales. The expenses of other executives and general staff are based on the proportion of the sales revenue of the product as the cost driver.

\subsection{Multi-product comprehensive cost accounting and profit analysis system architecture}

For large energy companies, due to the coexistence of multiple production devices and the large variety of final products, accounting statements and accounting methods based on activity-based costing cannot clearly reflect the profit contribution of each product, resulting in the management's inability to accurately conduct production capacity, business strategy, etc. Decision-making. Therefore, approving the cost of each product is the first step, and analyzing the profit contribution (loss) of each product is the key content. The multi-product comprehensive cost accounting and profit analysis system is an analysis system that effectively analyzes the profit contribution (loss) of various products of an enterprise (see Table 1).

Table 1. Multi-product comprehensive cost accounting and profit analysis system architecture

\begin{tabular}{|c|c|c|c|c|c|}
\hline \multicolumn{2}{|c|}{ Cost analysis } & \multicolumn{2}{|r|}{ Accounting } & \multicolumn{2}{|r|}{ Profit Analysis } \\
\hline $\begin{array}{c}\text { Serial } \\
\text { number }\end{array}$ & product & $\begin{array}{c}\text { Serial } \\
\text { number }\end{array}$ & Financial Statements & $\begin{array}{c}\text { Serial } \\
\text { number }\end{array}$ & Profit Analysis \\
\hline 1 & $\begin{array}{c}\text { Product } \\
\text { category A }\end{array}$ & 1 & Sales revenue & 1 & Accounting profit \\
\hline & $\begin{array}{l}\text { Analysis } \\
\text { caliber a }\end{array}$ & 2 & Production summary & 2 & $\begin{array}{c}\text { Comprehensive cost-profit } \\
\text { analysis } \\
\end{array}$ \\
\hline & $\begin{array}{l}\text { Analysis } \\
\text { caliber b }\end{array}$ & 3 & Management costs & 3 & Difference analysis \\
\hline & $\ldots$ & 4 & Financial expenses & & $\ldots \ldots$ \\
\hline 2 & $\begin{array}{c}\text { Product } \\
\text { category B }\end{array}$ & 5 & $\begin{array}{c}\text { Depreciation of fixed } \\
\text { assets }\end{array}$ & & \\
\hline 3 & $\begin{array}{c}\text { Product } \\
\text { category C }\end{array}$ & & & & \\
\hline
\end{tabular}

\subsection{Analysis of profit variance}

Since full production and full sales are a hypothetical condition, there is a difference between the total profit of the comprehensive cost statement and the total profit of the accounting statement. The main influencing factors are book inventory and book production cost, book inventory and actual production cost, and the impact of production and sales differences on period expenses Wait. Through profit difference analysis, the profit contribution or loss of each product can be clearly listed, and it can be analyzed from the perspectives of cost control, inventory management, and period expenses, and provide scientific and accurate data support for business management and business decisionmaking. 


\subsection{Cost control generation mechanism-dynamic optimization}

In the target cost management based on activity-based costing, the evaluation of the completion of the cost targets of each responsibility center is the analysis of the causes and consequences of the cost after the cost occurs. On the one hand, it is to distinguish responsibilities and implement rewards and punishments; on the other hand, The value analysis of the operation chain can be carried out to determine which operations provide services for the formation of the value of the final product, eliminate unnecessary or non-value-added operations, and at the same time, reduce the cost consumption of necessary but not value-added operations for the enterprise, and realize the optimized management of the operation chain . Therefore, in order to combine the target cost management and operation cost under the internal marketization, the responsibility center to which the target cost is decomposed and the operation center divided by operation costing must be coordinated and correspond to each other, and the responsibility center and the operation center must be coordinated. Control, so that the information of operating cost accounting meets the requirements of the assessment of the responsibility center. The basic idea of target cost management based on activity-based costing is shown in Figure 1.

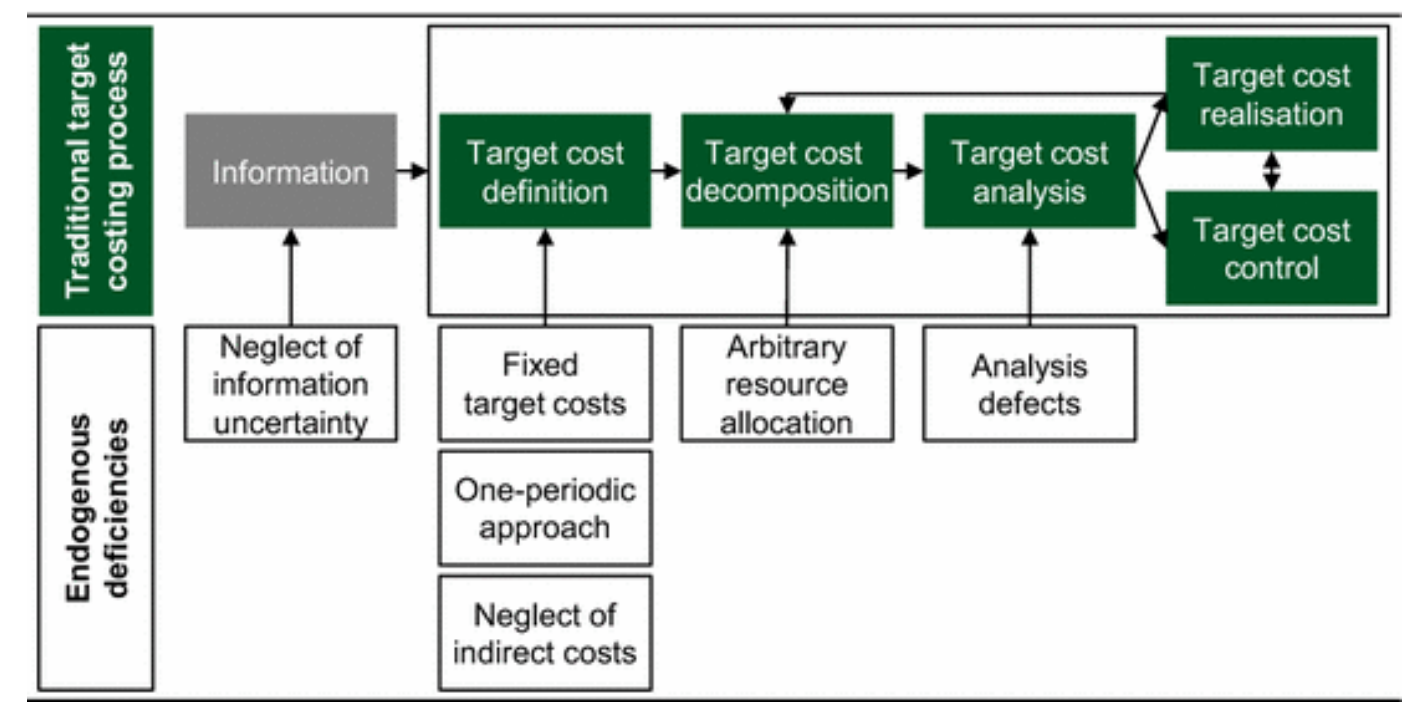

Figure 1. Evaluation flow chart of target cost control based on activity costing

Using the effective application of the comprehensive cost accounting and profit analysis system, we have a clear grasp of the profit contribution (loss) of the company's products, while keeping up with market changes, combining with the scientific forecast of the market later, and constantly making dynamic adjustments on the basis of a comprehensive budget. The main process is as follows: before the beginning of an accounting cycle, summarize the actual operating conditions and cost control conditions of the previous cycle, and combine the later market forecasts to formulate the operating target profit for the next accounting cycle. This is the operating target profit of the authorized unit in an accounting period, usually one year and broken down by month. Operating target profits, incentive policies, and cost accounting systems have formed a very close coupling and mutual promotion relationship (as shown in Figure 2). 


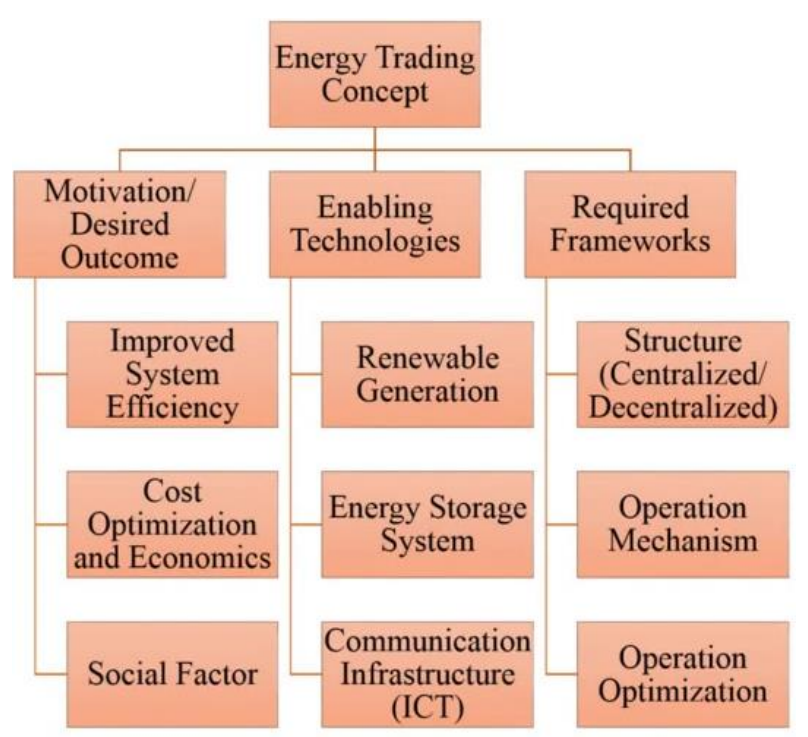

Figure 2. Dynamic optimization structure of cost control generation mechanism

\section{Conclusion}

In the process of enterprise cost accounting and control, cost accounting belongs to the important core and key of enterprise finance, and it shows important value in enterprise management and decision-making. As an enterprise, it is necessary to realize an all-round understanding of the accounting costing work according to the actual situation based on the basis of the market and the modern economy, and in-depth analysis and understanding of the problems that arise in it, and finally take corresponding measures according to the actual situation. Measures, on the basis of engineering and cost details, form a complete corporate accounting costing system, continuously promote the economic development and progress of the enterprise, and realize its social and economic benefits.

\section{References}

[1] Ye Qing, Guo Xinxin. Research on the impact of tax reduction and fee reduction on corporate accounting under the background of fiscal and taxation reform. Friends of Accounting, Vol. 11 (2019) No.14, p. 5 19.

[2] Yu Ji. Analysis on the Financial System of Rural Water Conservancy Project Enterprises under the Background of New Economy_Comment on "Agricultural Enterprise Accounting". Journal of Irrigation and Drainage, Vol. 40 (2021) No. 8, p.1 - 19.

[3] Qi Ruifu, Chen Chunhua. The evolution path of China's management model under the background of economic globalization_-Based on the perspective of enterprise management. Enterprise Economics, Vol. 39 (2020) No. 11, p.11 - 22.

[4] Wu Changqi, Shi Lang, Zhang Kunxian. Research on the Internationalization of Crowdfunding Platforms in the Context of Digital Economy_ B Based on the Perspective of Value Co-creation. Economics and Management Research, Vol. 41 (2020) No. 6, p. 16 - 29.

[5] Zhou Meng. Research on the Establishment and Operation Skills of Multinational Corporation Emergency Governance Architecture under the Thinking of Safety Development_Comment on "Governance, Development and Security: China and Global Economic Governance in the New Era". Journal of Safety and Environment, Vol. 20 (2020) No. 4, p. 1 - 8.

[6] Luo Juan. Limitations and Suggestions for Improvement of Cost Management Accounting Course Teaching Based on the Background of Big Data. Educational Research, Vol. 2 (2019) No. 9, p. 2 - 17.

[7] Juan Luo. Limitations and Suggestions for Improvement of Cost Management Accounting Course Teaching Based on the Background of Big Data. Educational Research, Vol. 2 (2019) No. 9, p. 14 - 29.

[8] Hu Fujiao. Research on the Implementation System of Financial Shared Services Based on Random Effects Model--A Review of "Tax Accounting". Chemical Reagents, Vol. 42 (2020) No. 1, p.1 - 11. 